\title{
Influence of photobiomodulation and vitamin D on osteoblastic differentiation of human periodontal ligament stem cells and bone-like tissue formation through enzymatic activity and gene expression
}

https://doi.org/10.1515/bmc-2020-0016

received October 5, 2020; accepted November 9, 2020.

\begin{abstract}
Background: Human periodontal ligament stem cells (HPDLSCs) are a unique population of mesenchymal stem cells (MSCs). Recently, the positive effects of photobiomodulation on the regulation of MSCs proliferation and osteogenic differentiation have gained significant attention. This study aimed to assess the effects of photobiomodulation and vitamin D (as an anabolic factor) on HPDLSCs for bone regeneration.
\end{abstract}

(2) Methods: HPDLSCs were collected, isolated, and characterized and then divided into six groups: groups I and II, control and $\left(10^{-7} \mathrm{Mol}\right)$ vitamin D, respectively; group III, irradiation at $1 \mathrm{~J} / \mathrm{cm}^{2}$ of $808-\mathrm{nm}$ diode laser; group IV, irradiation at $1 \mathrm{~J} / \mathrm{cm}^{2}$ and culture with vitamin $\mathrm{D}$; group V, irradiation at $2 \mathrm{~J} / \mathrm{cm}^{2}$, and group VI, irradiation at $2 \mathrm{~J} / \mathrm{cm}^{2}$ and culture with vitamin D. Cell viability assay was measured through MTT assay and cell growth curve. Alkaline phosphatase (ALP) enzyme activity and mRNA levels of RUNX2, collagen 1 (Col-1), ALP, and osteonectin were also assessed.

(3) Results: Photobiomodulation at 1 and $2 \mathrm{~J} / \mathrm{cm}^{2}$ combined with vitamin D significantly promoted HPDLSC proliferation (in MTT assay and cell growth curve results) and osteogenic differentiation (through the gene

\footnotetext{
*Corresponding author: Latifa Mohamed Abdelgawad, Professor of Medical Laser Applications, National Institute of Laser Enhanced Sciences (NILES), Cairo University, Giza, Egypt, E-mail: latifa@niles.edu.eg

Asmaa Mohamed Abdelaziz, Master degree candidate in Medical Laser Applications Department, National Institute of Laser Enhanced Sciences (NILES), Cairo University, Giza, Egypt

Dina Sabry, Professor of Medical Biochemistry and Molecular Biology, Faculty of Medicine, Cairo University, Giza, Egypt Marwa Abdelgwad, Lecturer of Medical Biochemistry and Molecular Biology, Faculty of Medicine, Cairo University, Giza, Egypt
}

expression of RUNX2, Col-1, ALP, and osteonectin levels ( $\mathrm{p}$ $<0.05)$.

(4) Conclusion: Laser irradiation at $2 \mathrm{~J} / \mathrm{cm}^{2}$ combined with vitamin D3 enhanced osteoblast differentiation and proliferation of cultured HPDLSCs and thus could further substitute bone grafting.

Keywords: Low-level laser; Dental Stem Cells; RUNX2; Osteonectin; Growth curve.

\section{Introduction}

Cell-based bone tissue engineering emerges as a potential alternative as it aims to generate new cell-driven, functional tissue rather than fill a defect with a nonliving graft material that usually ranges from natural autologous or allogeneic or xenogeneic graft materials to synthetic bone graft materials [1].

Stem cells from dental tissues have been evaluated as reliable candidates in tissue regeneration, primarily as they can be obtained from unnecessary organs, such as the third molars, unlike other sources of mesenchymal stem cell (MSC) (as the bone marrow or adipose tissue), which is a comprehensibly complicated harvesting process for patients $[2,3]$.

Several studies have isolated and used dental stem cells for bone regeneration. Seo et al. pioneered the proven stemness of the multipotent cells presented in periodontal ligament (PDL) tissues isolated from the middle third of the root surface of the extracted tooth. Subsequently, PDLs were used for its proven capability of tissue regeneration as it is rich in periodontal stem cells, which can be easily isolated and cultured in vitro for future use in vivo or in tissue banking [4-8].

Stages of osteoblast differentiation of stem cellsinclude immature osteoprogenitor, mature osteoprogenitor, 
preosteoblasts, mature osteoblasts, and finally osteocytes. RUNX2 serves as a master transcription factor of osteoblast differentiation at the early stage in the commitment of MSCs to the osteoblast lineage and through the expression of bone matrix genes as collagen1. Moreover, RUNX2 is a regulator of bone formation resulting from differentiated osteoblasts after maturation. Collagen-1 (Col-1) is the most common matrix protein that plays a role in cell adhesion, proliferation, and differentiation of the osteoblast phenotype and is produced during early osteogenic stem cell differentiation [9].

Osteonectin $(\mathrm{ON})$ is known as secreted protein acidic and rich in cysteine and secreted by osteoblasts. ON gene expression leads to binding of collagen and hydroxyapatite crystals together thus promoting mineralization of immature bone. ON is considered a special indicator for the initial growth of hydroxyapatite crystals (the spark for the mineralization process) [10].

Studies have proven that vitamin D has a direct anabolic effect on osteoblasts and can increase bone growth indirectly through increased calcium absorption [11].

Furthermore, 1,25- $(\mathrm{OH}) 2 \mathrm{D} 3$, the active form of vitamin $\mathrm{D}$, has been demonstrated to stimulate in vitro differentiation of MSCs into osteoblasts, mainly through binding to its nuclear vitamin $\mathrm{D}$ receptor, leading to expression of osteogenic genes (e.g., RUNX2, Col-1, osteopontin, ON, and alkaline phosphatase [ALP]), which were upregulated as in previous studies [12,13].

MSC differentiation and proliferation can be activated by physical factors such as light-emitting diode (LED), photobiomodulation therapy (PBM), electromagnetic fields, and ultraviolet irradiation as well as by the presence of specific proteins such as the Bone Morphogenetic Protein. Because the use of these proteins increases the treatment cost, PBM can be a suitable alternative to obtain osteoblasts and their de novo calcification [14-17].

PBM is a nonthermal process (caused by light photons of LED and low laser level) involving endogenous chromophores (e.g., cytochrome $\mathrm{C}$ oxidase and intracellular water), eliciting photophysical and photochemical events at various biological scales $[18,19]$.

Numerous studies have been conducted for using aiding factors with dental stem cells for bone regeneration. Studies have shown the impact of using vitamin D with dental stem cells [12,13] and other studies using PBM (using different types and low-energy wavelength lasers) to enhance the proliferation and differentiation of dental stem cells but, no data are available on the combined use of all these factors.

This is the reason that a new era of regenerative dentistry is directed to the use of dental stem cells combined with osteoconductive materials as vitamin D (to increase the ability of dental stem cells for osteogenic differentiation) with PBM effect of laser.

Aim of the study: Evaluation of the effect of photobiomodulation and vitamin D on HPDLSCs proliferation and osteogenic activity.

Null hypothesis: Neither photobiomodulation nor vitamin D has effect on HPDLSCs osteogenic differentiation when used separately or combined together than HPDLSCs used alone.

\section{Materials and Methods}

\section{Human periodontal ligament stem cells (HPDLSCs) isolation and culturing}

Sound impacted third molars were collected immediately after extraction from healthy adult female patients (20-25 years) from the outpatient clinic of Cairo University and transferred into the basic medium RPMI-1640 with L-Glutamine (BioWhittaker®, Lonza, USA, catalog number (cat\#) 12-702F) with 10\% fetal bovine serum (LSP ${ }^{\circledR}$, cat\#S001B-BR) and $1 \%$ penicillin/streptomycin (Biowest ${ }^{\circledR}$ USA, cat\# L0018-100).

Under the sterile condition, working within a biohazard laminar flow hood (Thermo Fisher Scientific ${ }^{\circledR}$, USA). Teeth were washed with phosphate buffer saline (BioWhittaker ${ }^{\circledR}$, Lonza, USA cat\#: 17-516F). A sterile scalpel blade no. 15 was used to gently scrape PDL from the middle third of roots and finally slice them into small $\left(1 \mathrm{~mm}^{3}\right)$ pieces.

Then, PDL tissues were incubated into collagenase type II (Sigma Aldrich, USA) for $2 \mathrm{~h}$ at $37^{\circ} \mathrm{C}$, centrifuged, filtered, and resuspended until the pellet was formed. The cell pellet was plated and cultured in a density of $15-30 \times 10^{3} \mathrm{cells} / \mathrm{cm}^{2}$ in basic medium and incubated in the culture at $37^{\circ} \mathrm{C}$ with $5.5 \% \mathrm{CO}_{2}$ and $90 \%-95 \%$ humidity. The culture medium was changed every three days until $80 \%-95 \%$ confluence of the cell was achieved [24].

Ethical approval: The research related to human use has been complied with all the relevant national regulations, institutional policies and in accordance the tenets of the Helsinki Declaration, and the protocol approved by the ethics committee of National Institute of Laser Enhanced Science (NILES, REC), Cairo University, Egypt, on March 11 (identification number code 019026). All procedures were performed in the Medical Biochemistry and Molecular Biology Department (tissue culture unit) of the Faculty of Medicine, Cairo University, Egypt. 
Table 1: showing study design and contents for each culture well group.

\begin{tabular}{lllll}
\hline $\begin{array}{l}\text { Groups / } \\
\text { content }\end{array}$ & HPDLSC & Vitamin D & $\begin{array}{l}\text { PBM 1J/ } \\
\text { cm2 }\end{array}$ & $\begin{array}{l}\text { PBM 2J/ } \\
\text { cm2 }\end{array}$ \\
\hline Group I & Yes & No & No & No \\
Group II & Yes & Yes & No & No \\
Group III & Yes & No & Yes & No \\
Group IV & Yes & Yes & Yes & No \\
Group V & Yes & No & No & Yes \\
Group VI & Yes & Yes & No & Yes \\
\hline & & & &
\end{tabular}

Informed consent: Informed consent has been obtained from all individuals included in this study.

\section{Characterization of HPDLSCs}

\section{Immunological characterization of HPDLSCs}

Fluorescence-activated cell sorting analysis was used to confirm surface antigens specific to CD105 (R\&D Systems, USA; cat \#, FAB1320F-025), and stem cells marker as CD29 (R\&D Systems, USA cat \#FAB2405P-025) and was negative to CD 45 (R\&D Systems, USA; cat \# FAB114A), excluding hematopoietic, endothelial cells.

\section{Phonotypical characterization of HPDLSCs}

Subsequent culture of HPDLSCs were examined under an inverted microscope (Leica ${ }^{\circledR}$, Germany) to confirm the shape of stem cells and its special characters (plastic adherence, spindle fusiform shape) of stem cells .HPDLSCs were assessed under inverted microscope as in lower section in figure 1, whereas HPDLSC made colonies (as a CFU cells), expanded by time to form a fusiform like cells adherent to the culture wells at day 21 of culture [25].

\section{Differentiation media}

Additionally, HPDLSCs were recultured in osteogenic differentiation media (glycerol 2-phosphate disodium salt hydrate, Sigma ${ }^{\circledR}$, USA), supplemented with $10 \mathrm{mM}$ b-glycerophosphate, $0.05 \mathrm{mM}$ ascorbic acid, and $100 \mathrm{mM}$ dexamethasone and divided into six groups and cultured on six-well plates (for further real-time polymerase chain reaction [RT-PCR] process) and 96-well plates (for future MTT assay) for 21 days.

\section{Vitamin D preparation}

An active form of vitamin D3 $\left(1,25-(\mathrm{OH})_{2}\right)$ (cholecalciferol [oily form] (PH, Eur, India) was used in the study, with dose of $10^{-7} \mathrm{Mol}$, and distributed in six wells as $10000 \mathrm{I.U}$ but in 96 wells as 1000 I.U [26].

\section{Cell culture groups}

Furthermore, 96-well tissue culture plates were equally divided into six groups as follows when passages 3-5 of PDLSCs were achieved and mainly passage 4:

Group I, a control group without irradiation; group II, HPDLSCs with vitamin D alone, without irradiation; group III, HPDLSCs with laser irradiation at $1 \mathrm{~J} / \mathrm{cm}^{2}$; group IV, HPDLSCs cultured with vitamin D and laser irradiation at $1 \mathrm{~J} / \mathrm{cm}^{2}$; group $\mathrm{V}$, irradiation at $2 \mathrm{~J} / \mathrm{cm}^{2}$; and group $\mathrm{VI}$ : vitamin $\mathrm{D}$ and laser irradiation at $2 \mathrm{~J} / \mathrm{cm}^{2}$.

\section{Laser irradiation}

The culture dishes were wrapped within the dark paper sheets with a hole of a diameter corresponding to the diameter of the laser spot area of the headpiece to avoid energy dispersion.

Cells were irradiated with a diode laser $\left(\mathrm{SOLASE}^{\circledR}\right.$, LAZON Medical Laser Corporation, supplied from Mcs, dental sector) in continuous wave mode parameters: 100 $\mathrm{mW}$, wavelength of $808 \mathrm{~nm}$, spot area of $0.5 \mathrm{~cm}^{2}$, and irradiation at 1 and $2 \mathrm{~J} / \mathrm{cm}^{2}$. Cells were double irradiated (at 0 and $48 \mathrm{~h}$ ) with laser probe fixed perpendicular to each plate, and irradiation was conducted in dark conditions. The cells were distributed as there were empty wells between seeded well cells to minimize the unintentional dispersion of light between wells during laser application [27].

\section{Cell viability}

MTT assay was used in the analysis, at $24 \mathrm{~h}$ and 7, 14, and 21 days after the first laser application, which was used to assess cell metabolic activity through the number of viable cells, and absorbance was directly proportional to the number of living cells in culture. Cells were cultured 
Table 2: PCR gene primers that were used.

\begin{tabular}{lll}
\hline RUNX2 & Forward: & $\begin{array}{l}\text { Reverse: } \\
\text { 5'-TCCCTAAAGTCACTCGGTATGTGTA-3' }\end{array}$ \\
\hline 5steonectin & Forward 5'-TGCATGTGTCTTAGTCTTAGTCACC-3' & Reverse: 3'-GCTAACTTAGTGCTTACAGGAACCA-5' $^{\prime}$ \\
Col-1 & Forward: 5'-AAAGTGAGAACGGGGAACCT-3' & Reverse: 5'-GATGCAAAGCCAGAATGGAT-3' \\
ALP & Forward: 5'-CTGCCATCCTGTATGGCAATG-3' & Reverse: 5'-AGACTGCGCCTGGTAGTTGTTG-3' \\
\hline
\end{tabular}

in 96-well plates for each time point, at a density of $1 \times 10^{3}$ cells/well, using MTT reagent (TACS, Trevigen, Gaithersburg, USA), and absorbance of the samples was monitored in an ELISA reader (Stat Fax 2200, Awareness Technologies, Florida, USA) at $450 \mathrm{~nm}$ [28].

\section{Cell growth curve}

Cells were seeded in triplicate in 48-well microplates (8 $\times 10^{3}$ cells/well) in the appropriate culture medium and trypsinized and counted in a hemocytometer with trypan blue at 7,14, and 21 days [29].

\section{Quantitative RT-PCR for osteogenic genes (RUNX2, Col-1, and osteonectin)}

Total cellular RNA for RUNX2, Col-1, ALP, and ON were extracted using GF-1 Nucleic Acid Extraction Kits (Vivantis ${ }^{\circledR} \quad$ Technologies, USA,cat\#GF-TR-050) and reverse transcribed using a complementary DNA master (SensiFAST ${ }^{\text {тм }}$ One-Step Kit, USA,cat \# PI-50217 V).

PCR assays were conducted according to the manufacturer protocol in real-time PCR device (Step One Applied Biosystems, USA).

The human-specific PCR primers of RUNX2, Col-1, ALP, and osteonectin were used (TaqManGene, Applied Biosystems, CA, USA). PCR primers of genes that were used are presented in Table 2.

The RT reaction was followed by a real-time PCR with a SYBR Green assay performed on an Applied Biosystems (Step One System, SDS software version 2.1 and RQ Manager 1.2). GAPDH was used as an endogenous reference control gene for normalization control [30].

\section{ALP enzyme activity}

Particularly, 96-well culture plates for each time point (7, 14, and 21 days) were seeded with $1 \times 10^{3}$ cells/well, homogenized in $50-\mu \mathrm{L}$ assay buffer, centrifuged for 3 min. Alkaline Phosphatase Assay Kit (Amplite ${ }^{\mathrm{TM}}$ AAT Bioquest, Inc., USA cat\# 11950) was used by adding para-nitrophenylphosphate, a chromogenic phosphatase substrate, and then incubated at $37^{\circ} \mathrm{C}$ for $10-30 \mathrm{~min}$ and measured levels of ALP documented in kilo unit (KU)/100 $\mathrm{mL}$ [31].

\section{Mineralization}

Calcium deposition as a final product of the osteogenic differentiation process was assessed using alizarin red $\mathrm{S}$ staining on day 21. HPDLSCs were stained with a solution of $1 \%$ alizarin red S (Bio Basic Inc., Canada) for $3 \mathrm{~min}$ at room temperature and washed with distilled water [32].

\section{Statistical analysis}

All data are presented as mean \pm standard deviation , analyzed with Student's t-test for two groups of data or one-way analysis of variance with Turkey's post hoc test for multiple groups of data using GraphPad Prism version 7 , where $\mathrm{P}$ value was set as $(\mathrm{P}<0.05)$ to indicate a statistically significant difference.

\section{Results}

\section{Characterization of HPDLSC}

- Immunological characterization was assessed as PDLSC were negative to CD 45 surface antigen (a), positive to CD 29 surface antigen (b), and positive to CD105 (c), as shown in Figure 1a, b, and c.

- Phenotypical characterization of PDLSC was assessed under an inverted microscope as in the lower section in Figure 1, whereas PDLSC made colonies (e.g., CFU 

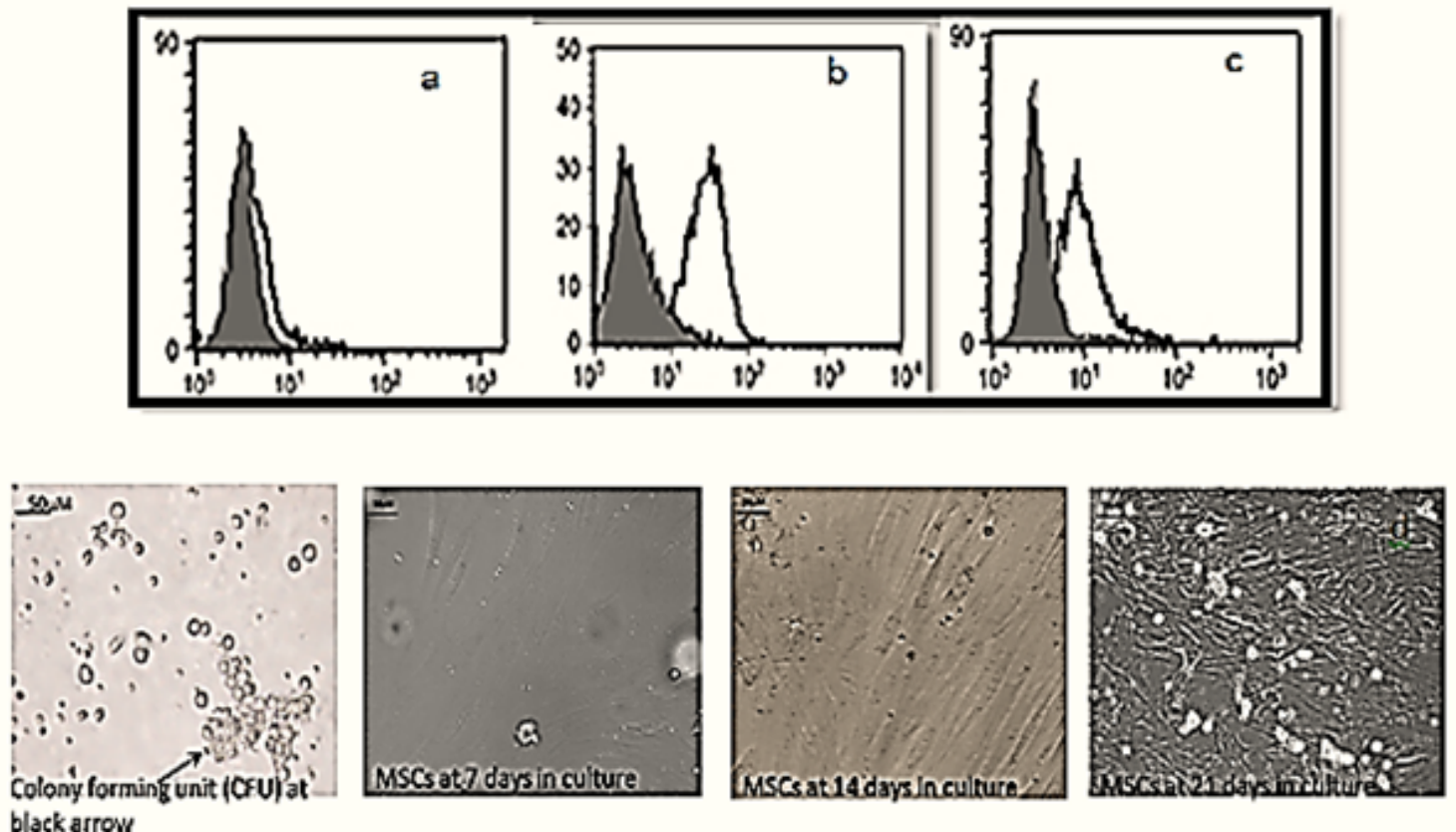

black arrow

Figure 1: Characterization of HPDLSC immunological characterization (upper section) (a, b, and c) and phenotypical characterization (lower section) (d).

cells), expanded by time to form fusiform-like cells adherent to the culture wells at day 21 of culture (Figure 1d).

\section{Cell viability was assessed via MTT assay}

It was measured at $24 \mathrm{~h}$ and 7, 14, and 21 days. It showed that, after laser irradiation of $1 \mathrm{~J} / \mathrm{cm}^{2}$ and $2 \mathrm{~J} / \mathrm{cm}^{2}$, MTT activity had a statistically significant increase at day 7 and day 14 compared to the control group $(p=0.005)$. Moreover, at day 14, there was a significant difference between groups III and V $(p=0.04)$ with the highest values of group $\mathrm{V}$, giving the idea that laser irradiation at 2 $\mathrm{J} / \mathrm{cm}^{2}$ increases proliferation of HPDLSC compared to laser irradiation at $1 \mathrm{~J} / \mathrm{cm}^{2}$. However, at 21 days, a significant value was obtained in the group with laser irradiation at 2 $\mathrm{J} / \mathrm{cm}^{2}$ and culture with vitamin $\mathrm{D}$ against vitamin $\mathrm{D}$ alone $(p<0.0001)$. These results confirmed a synergistic effect of low-level laser and vitamin D in enhancing proliferation of HPDLSC (Figure 2).

\section{Growth curve}

As shown in Figure 3, cell count increased throughout the study by reaching the highest numbers at day 21 . A statistically significant difference between all groups was noted $(\mathrm{p}<0.05)$. The group irradiated with $2 \mathrm{~J} / \mathrm{cm}^{2}$ and cultured with vitamin D showed 1.5-fold increase in cell count compared to the control group and nearly 1.3folds increase compared to the vitamin D alone group, denoting that laser irradiation added value to vitamin $\mathrm{D}$ in increasing HPDLSC count in osteoblastic differentiation media.

\section{RT-PCR analysis for osteogenic genes (RUNX2, Col-1, ALP, and osteonectin)}

\section{RUNX2}

RUNX2 gene measures as an early marker for bone differentiation. When measured on day 21, it showed a statistically significant difference between all groups ( $p$ $<0.0001$ ), especially groups irradiated with $2 \mathrm{~J} / \mathrm{cm}^{2}$ than those that were irradiated at $1 \mathrm{~J} / \mathrm{cm}^{2}$. It also showed a 


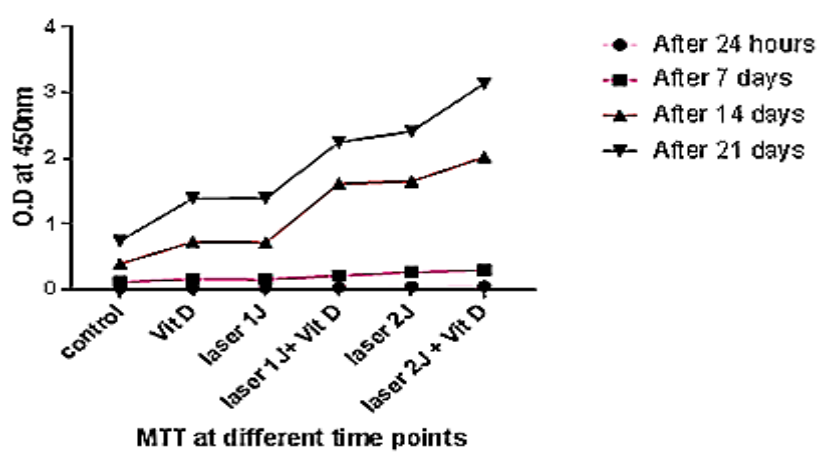

Figure 2: MTT assay measured at $24 \mathrm{~h}$ and 7, 14, and 21 days, showing that, at $24 \mathrm{~h}$, there was a statistically significant difference between group $\mathrm{VI}$ and the control and vitamin $\mathrm{D}$ group $(\mathrm{p}=0.008)$, while, at 21 days, there was a statistically significant difference between the treatment groups and control group $(p<0.0001)$. Data were expressed as mean \pm standard deviation (SD); a P-value $<0.05$ indicated statistical significance.

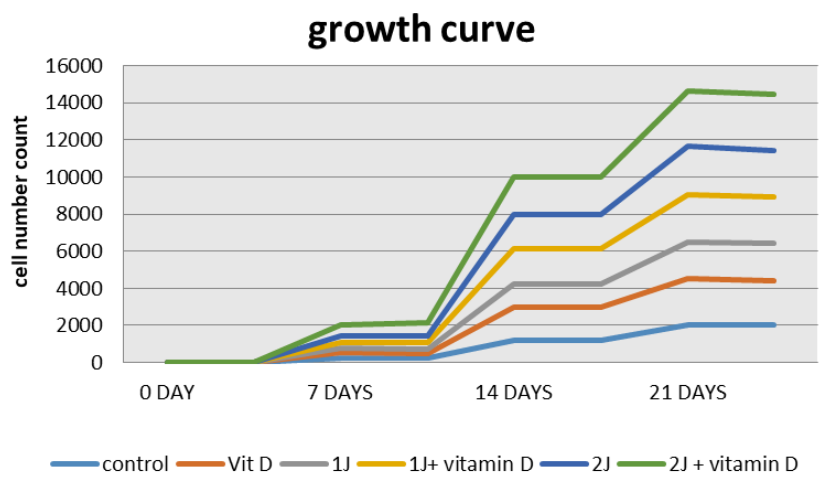

Figure 3: Growth curve for cell counts throughout the study showed a statistically significant difference between all groups $(p<0.05)$ with 1.5 -fold increase in cell count in the $2 \mathrm{~J} / \mathrm{cm}^{2}+$ vitamin $D$ group (group $\mathrm{VI}$ ) that in the control group.

significant difference in group with laser irradiation at 2 $\mathrm{J} / \mathrm{cm}^{2}$ and culture with vitamin $\mathrm{D}$ than in group $\mathrm{V}$ (laser irradiation only at $\left.2 \mathrm{~J} / \mathrm{cm}^{2}\right)(\mathrm{p}<0.0001)$.

Data analyzed showed that groups of vitamin D combined with HPDLSCs showed higher significance than groups with laser irradiation only or vitamin $\mathrm{D}$ alone (Figure 4).

Data were expressed as mean $\pm \mathrm{SD}$; a P-value $<0.05$ was significant. $\left(^{\star}\right)$ denotes significant difference versus control, (\#) denotes significant difference versus vitamin $\mathrm{D},(\$)$ denotes significant difference versus laser $1 \mathrm{~J} / \mathrm{cm}^{2}$, (@) denotes significant difference versus laser $1 \mathrm{~J} / \mathrm{cm}^{2}+$ Vitamin D, (\&) denotes significant difference versus laser $2 \mathrm{~J} / \mathrm{cm}^{2}$.

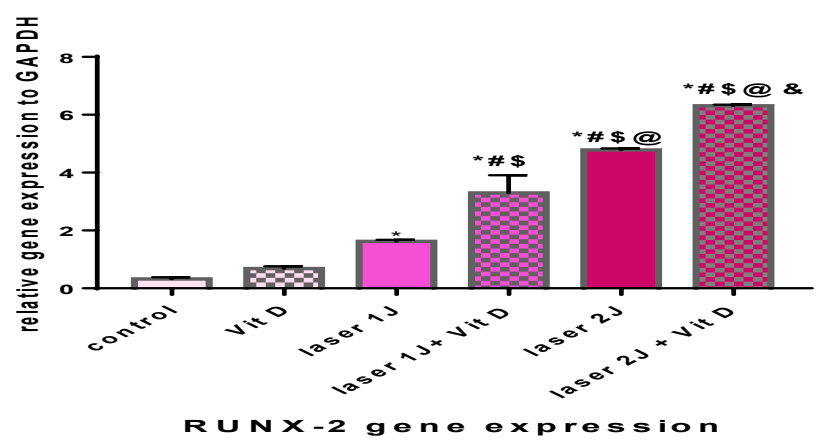

Figure 4: RUNX2 gene expression shows statistically significant difference between all groups ( $p$ 0.0001) with a significant difference between groups with laser irradiation of $1 \mathrm{~J} / \mathrm{cm}^{2}$ and $2 \mathrm{~J} /$ $\mathrm{cm}^{2}(p=0.0001)$. The values were measured relative to GAPDH gene levels.

\section{Col-1 and ALP}

Similar results as those of RUNX2 were obtained from Col-1 and ALP gene levels when measured at the end of the study ( $\mathrm{p}<0.0001$ ). We measured them as Col-1 and ALP genes and RUNX2 gene contribute to the early stages of the osteogenesis process. The results are shown in Figures 5 and 6.

\section{Osteonectin}

The late osteogenic marker was measured on day 21, and it showed a statistically significant difference between groups ( $\mathrm{p}<0.0001$ ).There was no significant difference between the vitamin $\mathrm{D}$ and control groups, indicating that vitamin D alone does not affect HPDLSC differentiation. However, with groups of laser irradiation at $2 \mathrm{~J} / \mathrm{cm}^{2}$ (groups $\mathrm{V}, \mathrm{VI}$ ), there were statistically different values against the control and vitamin D groups ( $\mathrm{p}=0.0001$ ) (Figure 7 ).

\section{ALP enzyme activity}

Day 7: There was no statistically significant difference between groups with laser irradiation of $1 \mathrm{~J} / \mathrm{cm}^{2}$ or that with culture of vitamin $\mathrm{D}$ and the control group, while significant values were observed in $1 \mathrm{~J} / \mathrm{cm}^{2}+$ vitamin $D$, $2 \mathrm{~J} / \mathrm{cm}^{2}$, and $2 \mathrm{~J} / \mathrm{cm}^{2}+$ vitamin D groups compared to the control group $(\mathrm{p}<0.05)$.

Moreover, on day 14, a highly significant difference was observed in the $2 \mathrm{~J} / \mathrm{cm}^{2}$ laser irradiated group and those with culture with vitamin D compared to the control and vitamin $\mathrm{D}$ alone groups $(\mathrm{p}=0.002)$. 


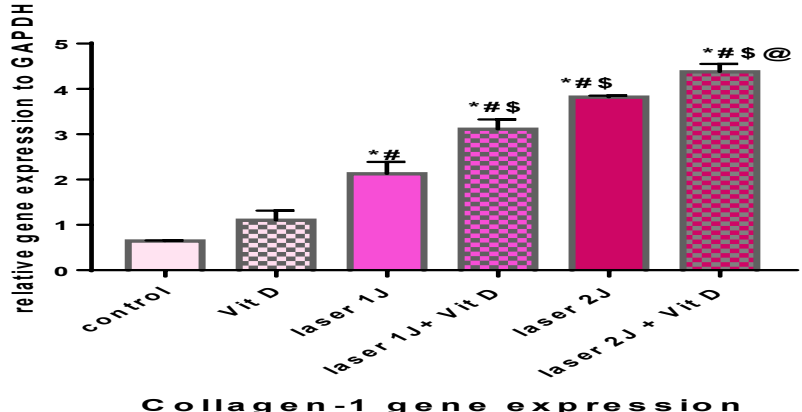

Figure 5: Col-1 gene expression showed a statistical difference between study groups $(\mathrm{p}<0.0001)$ with the highest values in group VI (2 J/ $\mathrm{cm}^{2}+$ vitamin D). Data were expressed as mean \pm SD; P-value $<0.05$ was significant. ( $\left.{ }^{\star}\right)$ denotes significant difference versus control. (\#) denotes significant difference versus vitamin D. (\$) denotes significant difference versus laser $1 \mathrm{~J} / \mathrm{cm}^{2}$. (@) denotes significant difference versus laser $1 \mathrm{~J} / \mathrm{cm}^{2}+$ vitamin $D$.

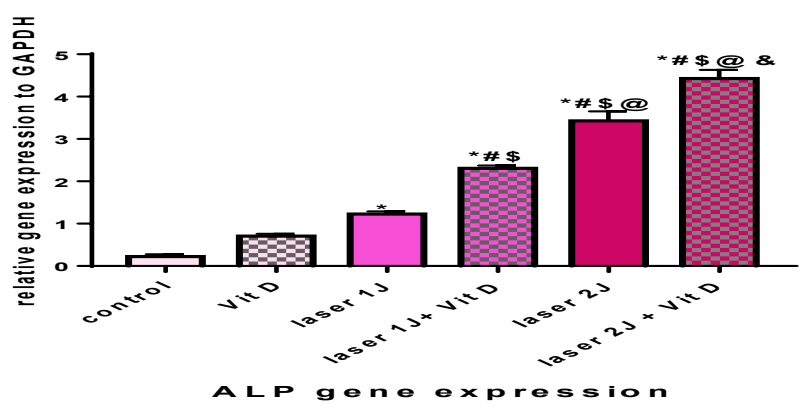

Figure 6: Alkaline phosphatase gene expression shows a statistically significant difference between all groups that in the control group ( $p<0.0001$ ), except for the vitamin $D$ alone group. Data were expressed as mean \pm SD; a $p$-value $<0.05$ was significant. $\left.{ }^{*}\right)$ denotes significant difference versus control. (\#) denotes significant difference versus vitamin D. (\$) denotes significant difference versus laser $1 \mathrm{~J} / \mathrm{cm}^{2}$. (@) denotes significant difference versus laser $1 \mathrm{~J} / \mathrm{cm}^{2}+$ vitamin D. (\&) denotes significant difference versus laser $2 \mathrm{~J} / \mathrm{cm}^{2}$.

On day 21, the group with laser irradiation of $2 \mathrm{~J} / \mathrm{cm}^{2}$ showed nearly 1.3-fold increase with a significant difference compared to the group with $1 \mathrm{~J} / \mathrm{cm}^{2}$ irradiation $(p<0.001)$, showing that the increase triggers desired biological reaction as indicated by Arndt-Schultz's law. However, the laser irradiation combined with vitamin D groups (groups IV and VI) also showed a significant difference $(p<0.0001)$ that confirmed the role of vitamin $D$ in enhancing the effect of low-level of laser irradiation on HPLSCs (Figure 8).

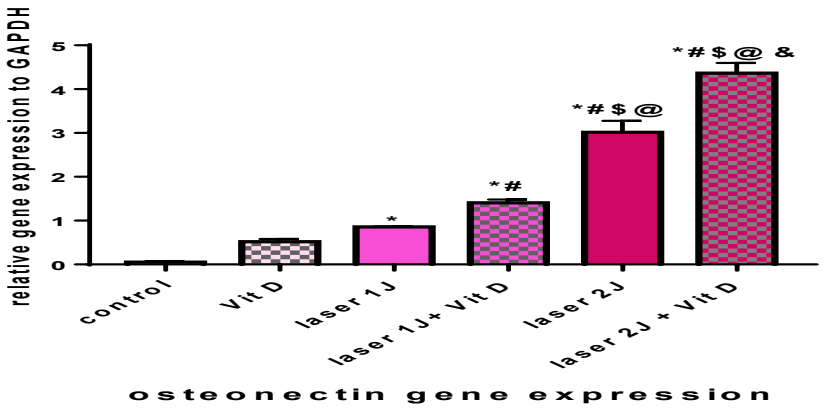

Figure 7: Osteonectin gene expression levels showed a statistically significant difference between groups $(p<0.0001)$. There was a highly significant difference between the laser $2 \mathrm{~J} / \mathrm{cm}^{2}+$ vitamin $D$ group and laser $1 \mathrm{~J} / \mathrm{cm}^{2}+$ vitamin $D$ group $(p<0.0001)$. Data were expressed as mean \pm SD; a p-value $<0.05$ was significant. $\left(^{\star}\right)$ denotes significant difference versus control. (\#) denotes significant difference versus vitamin D. (\$) denotes significant difference versus laser $1 \mathrm{~J} / \mathrm{cm}^{2}$. (@) denotes significant difference versus laser $1 \mathrm{~J} / \mathrm{cm}^{2}+$ vitamin D. (\&) denotes significant difference versus laser $2 \mathrm{~J} / \mathrm{cm}^{2}$.
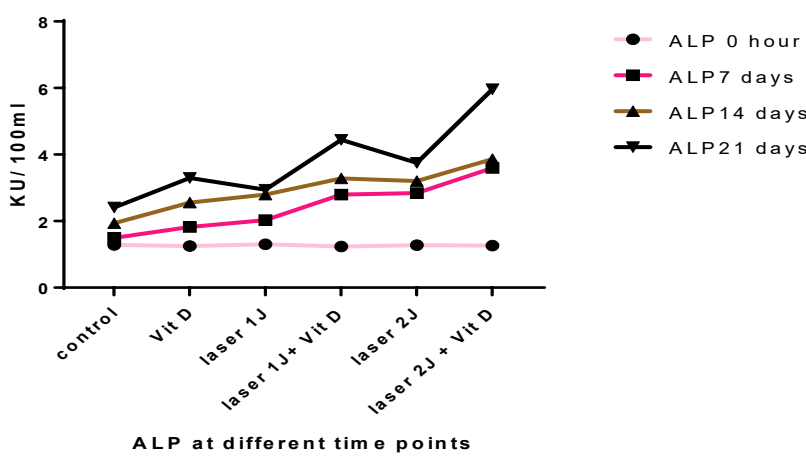

Figure 8: ALP enzyme activity levels measured at $0,7,14$, and 21 days with a highly significant difference between the $2 \mathrm{~J} / \mathrm{cm}^{2}$ group compared to the $1 \mathrm{~J} / \mathrm{cm}^{2}(\mathrm{p}<0.001)$ on day 21. Moreover, the $2 \mathrm{~J} /$ $\mathrm{cm}^{2}$ and culture with vitamin $\mathrm{D}$ group showed highly statistically significant difference than the control group $(p<0.0001)$. Data were expressed as mean $\pm \mathrm{SD}$; a P-value $<0.05$ was significant. $\left(^{*}\right)$ denotes significant difference versus control. (\#) denotes significant difference versus vitamin D.(\$) denotes significant difference versus laser $1 \mathrm{~J} / \mathrm{cm}^{2}$. (@) denotes significant difference versus laser $1 \mathrm{~J} / \mathrm{cm}^{2}+$ vitamin D. (\&) denotes significant difference versus laser $2 \mathrm{~J} / \mathrm{cm}^{2}$.

\section{Alizarin red S staining}

There was increased mineralization and calcium nodules formation in all study groups that was visible through alizarin red stained nodules. Mineralized nodules were formed in all groups with various degrees of stain intensity reflecting their variable calcium content. As shown in figure 22 (f) represents group VI $\left(2 \mathrm{~J} / \mathrm{cm}^{2}+\right.$ vitamin D) showed highest calcified nodules number and deeply stained than other groups. 

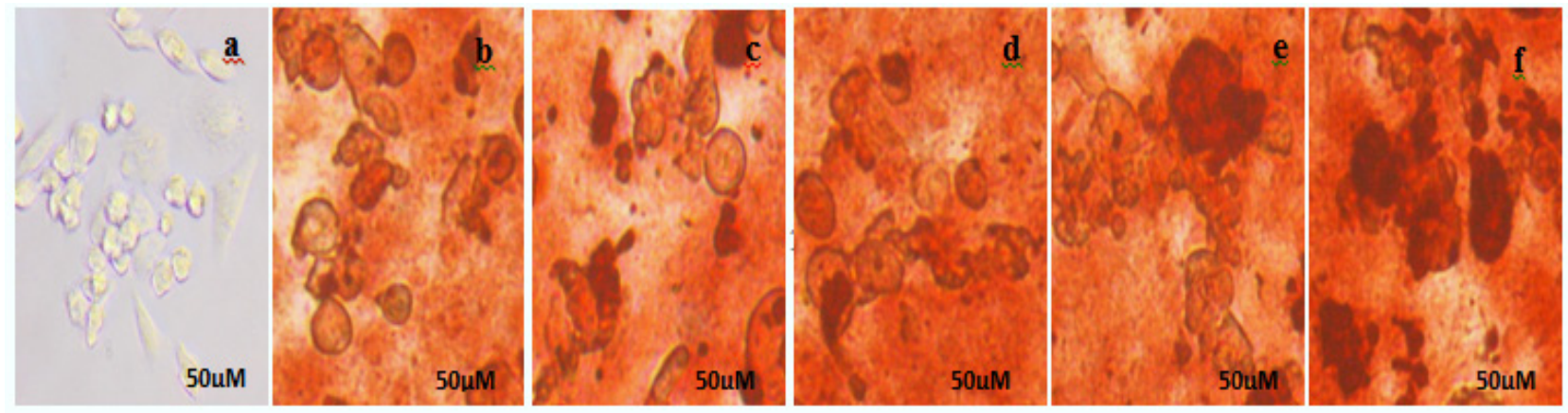

Figure 9: :Alizarin Red stain of the study group on day 21 under microscope with a magnification of X200.Alizarin red stain deeply stains calcium nodules formed after osteogenic differentiation where a: for control group, b:for vitamin D only group, $\mathbf{c}$ : for group $1 \mathrm{~J} / \mathrm{cm}^{2}$, d:for $1 \mathrm{~J} /$ $\mathrm{cm}^{2}+$ vitamin $D$, e:for $2 \mathrm{~J} / \mathrm{cm}^{2}$ group, f: group of vitamin $D$ and $2 \mathrm{j} / \mathrm{cm}^{2}$.

\section{Discussion}

Many studies and trials have been advocated for bone regeneration through different techniques. Dental stem cell therapy with aid of different materials and proteins and light therapy (low-level laser therapy) has been used to easily obtain and use dental stem cells than other sources of stem cells that may require aspiration of bone marrow(bone marrow stem cells) or liposuction (adipose stem cells).

Wu et al. in 2013 [19] studied HPDLSCs for osteogenic proliferation and differentiation, which was enhanced by low-level laser in constituent with this study, but the cultured cells were irradiated with $660 \mathrm{~nm}$. They concluded that irradiated cells at $2 \mathrm{~J} / \mathrm{cm}^{2}$ promoted HPDLSC proliferation. Moreover, they confirmed an increase in the osteogenic differentiation through alizarin red staining, and our study showed the same results. In our study, we used 808-nm low-level laser irradiation for its greater penetration depth and effect on HPDLSCs than $660 \mathrm{~nm}$.

Use of 808-nm infrared laser photobiomodulation was a result of previous studies that confirmed its effect for promoting the proliferation of stem cells via activation of cytochrome $\mathrm{C}$ oxidase (chromophore for red and near infrared light photons) and subsequently increases mitochondrial membrane potential, thus allowing the mitochondria to produce more ATP. The results obtained from this study of MTT assay, especially at day 21 (in group V compared to group III), were similar to those of earlier studies by Kreisler et al., who used different energy densities of 809-nm low-level laser (1.96, 3.92, and 7.84 $\left.\mathrm{J} \cdot \mathrm{cm}^{-2}\right)$ to irradiate HPDLSCs [33, 21].

The particular effect of PBM in promoting stem cell differentiation is proposed to be due to shifting the metabolic profile from glycolysis to oxidative phosphorylation (metabolic switch), which is a key factor in stem cell osteogenic differentiation that was confirmed by Wu et al [17]. Our findings are similar to those of an earlier study by Choi et al. [34], who found the stimulating effects of low-level laser irradiation occurred at energy densities of up to $4 \mathrm{~J} / \mathrm{cm}^{2}$, whereas the inhibitory effects of PBM occurred at higher energy doses according to Arndt's Schultz law. This was also confirmed by Bouvet-Gerbettaz et al. [35], who revealed a negative effect on osteoblast differentiation promotion with $808 \mathrm{~nm}$ at $4 \mathrm{~J} / \mathrm{cm}^{2}$.

Furthermore, PBM absorption of irradiation by structured intracellular water produces changes in molecular vibrational energy and affects the tertiary conformation of enzymes, ion channels, and other proteins. The relatively small changes can activate signaling pathways and further activation of transcription factors and changes in gene expression [36].

RUNX2 has been known as a master gene that orchestrates the osteogenic differentiation of MSCs. RUNX2 was measured in all test groups, showing high significance in group $\mathrm{V}\left(2 \mathrm{~J} / \mathrm{cm}^{2}\right)$ than group III $\left(1 \mathrm{~J} / \mathrm{cm}^{2}\right)$. These results agreed with those of a study by Peng et al. [37], who reported that 620-nm red-light LED irradiation promotes RUNX2 expression of bone marrow MSCs. Hong et al. [26] concluded that vitamin D3 of $10^{-7} \mathrm{M}$ concentration significantly upregulated Col-1 mRNA expression as in groups that were cultured with vitamin D (groups VI and IV) compared to groups that were laser irradiated only (groups V and III). Col-1 gene contributes to the early stages of bone matrix deposition.

At the beginning of matrix mineralization, genes for proteins such as osteonectin are expressed, but calcium deposition can be visualized once mineralization is completed, using alizarin red stain, as shown in this study 
results clearly among all groups with varying degrees representing the highest calcium nodules in group VI (2 $\mathrm{J} / \mathrm{cm}^{2}+$ vitamin D).

Studies that have described $1,25(\mathrm{OH})_{2} \mathrm{D} 3$ to increase MSC osteoblastic differentiation [13,38] used the active form of vitamin D as an osteoconductive factor in the cell therapy for bone regeneration. Additionally, a study conducted by Wang et al in 2018 [1] used the same vitamin D concentration we used in this study $\left(10^{-7} \mathrm{M}\right)$, showing that vitamin $\mathrm{D}$ treatment to periosteal stem cells increased ALP levels after osteogenic differentiation conditions, similar to those obtained from study groups containing vitamin D.

Moreover, Ji et al. in 2018 [39] elucidate the role of 1,25-D3 in osteogenic differentiation of HPDLSCs by upregulating Osteopontin and ALP enzymes and RUNX2 gene.

However, literature has limited data on the use of laser PBM with vitamin D. It showed good results, such as those in this study, through the expression of RUNX2 and Col-1 genes as early markers and expression of osteonectin gene as a late osteogenic marker compared with irradiated groups, cultured without vitamin D. Such studies needed more future trials to be used in upcoming applications of cell therapy in bone regeneration.

\section{Conclusion}

Vitamin D3 upregulates osteogenic proliferation and differentiation of HPDLSCs besides the PBM effect of different energies $\left(1\right.$ and $\left.2 \mathrm{~J} / \mathrm{cm}^{2}\right)$ with the greatest anabolic effect using $2 \mathrm{~J} / \mathrm{cm}^{2}$ low-level laser irradiation.

\section{Author contributions}

Prof dr. Larifa M. Abdelgawad: supervision, conceptualization, and resources. Dr. Asmaa M. Abdelaziz: visualization, resources, and writing-original draft preparation. Prof. Dr. Dina Sabry Abdullfattah: investigation, methodology, and project administration. Dr. Marwa M. Abdelgawd: data curation, formal analysis, and resources.

Conflict of interest: Authors state no conflict of interest

\section{References}

1. Wang YL, Hong A, Yen TH, Hong HH. Isolation of mesenchymal stem cells from human alveolar periosteum and effects of vitamin D on osteogenic activity of periosteum-derived cells. J Vis Exp. 2018 May;e57166(135):•••.

2. Dominici M, Le Blanc K, Mueller I, Slaper-Cortenbach I, Marini F, Krause D, et al. Minimal criteria for defining multipotent mesenchymal stromal cells. The International Society for Cellular Therapy position statement. Cytotherapy. 2006;8(4):315-7.

3. Mori G, Brunetti G, Oranger A, Carbone C, Ballini A, Lo Muzio L, et al. Dental pulp stem cells: osteogenic differentiation and gene expression. Ann N Y Acad Sci. 2011 Nov;1237(1):47-52.

4. Aydin S, Şahin F. Stem cells derived from dental tissues. Adv Exp Med Biol. 2019;1144:123-32.

5. Nakajima K, Kunimatsu R, Ando K, Ando T, Hayashi Y, Kihara T, et al. Comparison of the bone regeneration ability between stem cells from human exfoliated deciduous teeth, human dental pulp stem cells and human bone marrow mesenchymal stem cells. Biochem Biophys Res Commun. 2018 Mar;497(3):876-82.

6. Zhang J, Li ZG, Si YM, Chen B, Meng J. The difference on the osteogenic differentiation between periodontal ligament stem cells and bone marrow mesenchymal stem cells under inflammatory microenviroments. Differentiation. 2014 NovDec;88(4-5):97-105.

7. Seo BM, Miura M, Gronthos S, Bartold PM, Batouli S, Brahim J, et al. Investigation of multipotent postnatal stem cells from human periodontal ligament. Lancet. 2004 Jul;364(9429):149-55.

8. Szepesi Á, Matula Z, Szigeti A, Várady G, Szalma J, Szabó G, et al. In vitro characterization of human mesenchymal stem cells isolated from different tissues with a potential to promote complex bone regeneration. Stem Cells Int. 2016;2016:3595941.

9. Hong $\mathrm{HH}$, Hong A, Wang CC, Huang EW, Chiang CC, Yen TH, et al. Calcitriol exerts a mineralization-inductive effect comparable to that of vitamin $\mathrm{C}$ in cultured human periodontium cells. Am J Transl $\operatorname{Re}$ 2019;11(4):2304-2316. /ISSN:1943-8141/ AJTR0087080

10. Houreh AB, Labbaf S, Ting HK, Ejeian F, Jones JR, Esfahani MN. Influence of calcium and phosphorus release from bioactive glasses on viability and differentiation of dental pulp stem cells. J Mater Sci. 2017 Aug;52(15):8928-41.

11. Lichtenstein A, Ferreira-Júnior M, Sales MM, Aguiar FB, Fonseca LA, Sumita NM, et al.; Grupo de Estudos para o Uso Racional do Laboratório Clínico do Hospital das Clínicas da Faculdade de Medicina da Universidade de São Paulo. Vitamin D: non-skeletal actions and rational use. Rev Assoc Med Bras (1992). 2013 SepOct;59(5):495-506.

12. Posa F, Di Benedetto A, Colaianni G, Cavalcanti-Adam EA, Brunetti G, Porro C, et al. Vitamin D effects on osteoblastic differentiation of mesenchymal stem cells from dental tissues. Stem Cells Int. 2016;2016:9150819.

13. Posa F, Di Benedetto A, Cavalcanti-Adam EA, Colaianni G, Porro C, Trotta T, et al. Vitamin D promotes MSC osteogenic differentiation stimulating cell adhesion and $\alpha \mathrm{V} \beta 3$ expression. Stem Cells Int. 2018 Feb;2018:6958713. 
14. Nurković J, Zaletel I, Nurković S, Hajrović Š, Mustafić F, Isma J, et al. Combined effects of electromagnetic field and low-level laser increase proliferation and alter the morphology of human adipose tissue-derived mesenchymal stem cells. Lasers Med Sci. 2017 Jan;32(1):151-60.

15. Pinheiro CC, de Pinho MC, Aranha AC, Fregnani E, Bueno DF. Low power laser therapy: A strategy to promote the osteogenic differentiation of deciduous dental pulp stem cells from cleft lip and palate patients. Tissue Eng Part A. 2018 Apr;24(7-8):56975.

16. Marques MM, Diniz IM, de Cara SP, Pedroni AC, Abe GL, D'Almeida-Couto RS, et al. Photobiomodulation of dental derived mesenchymal stem cells: a systematic review. Photomed Laser Surg. 2016 Nov;34(11):500-8.

17. Wu JY, Chen CH, Yeh LY, Yeh ML, Ting CC, Wang YH. Low-power laser irradiation promotes the proliferation and osteogenic differentiation of human periodontal ligament cells via cyclic adenosine monophosphate. Int J Oral Sci. 2013 Jun;5(2):85-91.

18. Anders JJ, Lanzafame RJ, Arany PR. Low-level light/laser therapy versus photobiomodulation therapy. Photomed Laser Surg. 2015 Apr;33(4):183-4.

19. Pinheiro CC, Bueno DF. Alternative strategies for stem cell osteogenic differentiation. Osteogenesis and Bone Regeneration. IntechOpen; 2018. https://doi.org/10.5772/ intechopen.82333.

20. Zein R, Selting W, Hamblin MR. Review of light parameters and photobiomodulation efficacy: dive into complexity. J Biomed Opt. 2018 Dec;23(12):1-17.

21. Wang $Y$, Huang $Y$, Wang $Y$, Lyu $P$, Hamblin MR. Photobiomodulation of human adipose-derived stem cells using $810 \mathrm{~nm}$ and $980 \mathrm{~nm}$ lasers operates via different mechanisms of action. Biochim Biophys Acta, Gen Subj. 2017 Feb;1861(2):4419.

22. Ginani F, Soares DM, de Oliveira Rocha HA, de Souza LB, Barboza CA. Low-level laser irradiation induces in vitro proliferation of stem cells from human exfoliated deciduous teeth. Lasers Med Sci. 2018 Jan;33(1):95-102.

23. Gjerde C, Mustafa K, Hellem S, Rojewski M, Gjengedal H, Yassin MA, et al. Cell therapy induced regeneration of severely atrophied mandibular bone in a clinical trial. Stem Cell Res Ther. 2018 Aug;9(1):213.

24. Karamzadeh R, Eslaminejad MB, Aflatoonian R. Isolation, characterization and comparative differentiation of human dental pulp stem cells derived from permanent teeth by using two different methods. J Vis Exp. 2012 Nov;69:e4372.

25. Hajizadeh N, Madani ZS, Zabihi E, Golpour M, Zahedpasha A, Mohammadnia M. Effect of MTA and CEM on mineralizationassociated gene expression in stem cells derived from apical papilla. Iran Endod J. 2018;13(1):94-101.

26. Hong HH, Hong A, Yen TH, Wang YL. Potential osteoinductive effects of calcitriol on the m-RNA of mesenchymal stem cells derived from human alveolar periosteum. BioMed Res Int. 2016;2016:3529561.

27. Soares DM, Ginani F, Henriques ÁG, Barboza CA. Effects of laser therapy on the proliferation of human periodontal ligament stem cells. Lasers Med Sci. 2015 Apr;30(3):1171-4.

28. Othman A, Mubarak R, Sabry D. Fibroblast growth factor-6 enhances CDK2 and MATK expression in microvesicles derived from human stem cells extracted from exfoliated deciduous teeth. F1000 Res. 2018 May;7(622):622.
29. Baldión PA, Velandia-Romero ML, Castellanos JE. Odontoblastlike cells differentiated from dental pulp stem cells retain their phenotype after subcultivation. Int J Cell Biol. 2018 Feb;2018:6853189.

30. Dianzani F, Mandelli BF, Baron S, Malavasi F, Barbacane RC, Bocci V, et al. Journal of Biological Regulators \& Homeostatic Agents. J Biol Regul Homeost Agents. 2015 Jan;29(1).

31. Kim HB, Baik KY, Seonwoo H, Jang KJ, Lee MC, Choung PH, et al. Effects of pulsing of light on the dentinogenesis of dental pulp stem cells in vitro. Sci Rep. 2018 Feb;8(1):2057.

32. Kato H, Katayama N, Taguchi Y, Tominaga K, Umeda M, Tanaka A. A synthetic oligopeptide derived from enamel matrix derivative promotes the differentiation of human periodontal ligament stem cells into osteoblast-like cells with increased mineralization. J Periodontol. 2013 Oct;84(10):1476-83.

33. Kreisler M, Christoffers AB, Willershausen B, d'Hoedt B. Effect of low-level GaAlAs laser irradiation on the proliferation rate of human periodontal ligament fibroblasts: an in vitro study. J Clin Periodontol. 2003 Apr;30(4):353-8.

34. Choi EJ, Yim JY, Koo KT, Seol YJ, Lee YM, Ku Y, et al. Biological effects of a semiconductor diode laser on human periodontal ligament fibroblasts. J Periodontal Implant Sci. 2010 Jun;40(3):105-10.

35. Bouvet-Gerbettaz S, Merigo E, Rocca JP, Carle GF, Rochet N. Effects of low-level laser therapy on proliferation and differentiation of murine bone marrow cells into osteoblasts and osteoclasts. Lasers Surg Med. 2009 Apr;41(4):291-7.

36. Tsai SR, Hamblin MR. Biological effects and medical applications of infrared radiation. J Photochem Photobiol B. 2017 May;170:197-207.

37. Peng F, Wu H, Zheng Y, Xu X, Yu J. The effect of noncoherent red light irradiation on proliferation and osteogenic differentiation of bone marrow mesenchymal stem cells. Lasers Med Sci. 2012 May;27(3):645-53.

38. Zhou S, Glowacki J, Kim SW, Hahne J, Geng S, Mueller SM, et al. Clinical characteristics influence in vitro action of 1,25-dihydroxyvitamin $\mathrm{D}(3)$ in human marrow stromal cells. J Bone Miner Res. 2012 Sep;27(9):1992-2000.

39. Ji $Y$, Zhang $P$, Xing $Y$, Jia L, Zhang $Y$, Jia T, et al. Effect of $1 \alpha$, 25-dihydroxyvitamin D3 on the osteogenic differentiation of human periodontal ligament stem cells and the underlying regulatory mechanism. Int J Mol Med. 2019 Jan;43(1):167-76. 